\title{
Mitolactol/Doxorubicin/Vincristine Regimen
}

National Cancer Institute

\section{Source}

National Cancer Institute. Mitolactol/Doxorubicin/Vincristine Regimen. NCI Thesaurus. Code C161960.

A chemotherapy regimen consisting of mitolactol (dibromodulcitol), doxorubicin, and vincristine that may be used in the treatment of breast cancer. 